\title{
Evidência da ação antiparasitária da azitromicina na infecção experimental de camundongos pelo Plasmodium berghei
}

\author{
Experimental infection in mice by Plasmodium berghei: an evidence \\ of antiparasitic action of azithromycin
}

\author{
Erika Gakiya1, Lúcia Maria Almeida Braz¹, Vicente Amato Neto e Rita Cristina Bezerra1
}

Resumo A azitromicina debelou a infecção experimental de camundongos pelo Plasmodium berghei quando administrada, pela via oral e durante 28 dias, na dose de $100 \mathrm{mg} / \mathrm{kg}$, iniciada no mesmo dia em que os animais foram infectados. Mediante uso de $10 \mathrm{mg} / \mathrm{kg}$ houve insucesso. Os resultados obtidos suscitam investigações complementares sobre a referida atividade antiparasitária desse medicamento.

Palavras-chaves: Plasmodium berghei. Infecção experimental. Tratamento. Azitromicina.

Abstract Infections of Plasmodium berghei in mice was stopped by azithromycin which was administered orally in dosages of $100 \mathrm{mg} / \mathrm{kg}$, for 28 days. This antibiotic was given since the same day that the animals were infected. The outcome suggests the necessity of more investigations on this antiparasitic activity.

Key-words: Plasmodium berghei. Experimental infection. Azithromycin.

No Laboratório de Parasitologia do Instituto de Medicina Tropical de São Paulo são, basicamente, realizadas pesquisas relacionadas com diagnóstico e tratamento de doenças parasitárias. Estão disponíveis sistemas que permitem investigações efetuadas em modelos animais, permitindo a obtenção, com relativa simplicidade, de úteis verificações experimentais.

Nesse contexto ocorreram avaliações referentes a variados fármacos, com base em informações consignadas na literatura científica ou advindas de clínicos e de outros profissionais que notaram acontecimentos merecedores de especulações.
Realizamos algumas apreciações utilizando a azitromicina, antibiótico do grupo dos macrolídeos, sendo que na infecção devida ao Plasmodium berghei ocorreu resultado digno de registro, agora apresentado.

Esse antimicrobiano, in vitro ou em animais, opôs-se eficientemente à infecção pelo Toxoplasma gondii ${ }^{123} \mathrm{e}$, no que tange à malária, teve capacidade profilática relacionada com $P$. falciparum cloroquina-resistente ${ }^{4}$. $O$ mecanismo segundo o qual exerce atividade antimalárica não é conhecido, podendo talvez agir como um lipossomotrópico, à semelhança do que se propõe para explicar como a cloroquine age ${ }^{4}$.

\section{MATERIAL E MÉTODOS}

Utilizamos 80 camungondos albinos, machos, da linhagem Balb/C, pesando cada um aproximadamente $20 \mathrm{~g}$. Os animais foram fornecidos pelo Biotério Central da Faculdade de Medicina da Universidade de São Paulo. Empregamos $5.10^{3}$ formas de $P$. berghei, inoculadas pela via intraperitoneal em cada roedor, provenientes de cepa rotineiramente mantida no Laboratório.

Constituímos quatro Grupos, compostos por 20 animais conforme a seguinte especificação: G1 infectados; administração de $10 \mathrm{mg} / \mathrm{kg} / \mathrm{dia}$ de azitromicina diariamente; G2 - infectados; administração de 100mg/kg/dia; G3 - apenas infectados; G4 - apenas administração de $10 \mathrm{mg} / \mathrm{kg} / \mathrm{dia}$ ou $100 \mathrm{mg} /$ $\mathrm{kg} / \mathrm{dia}$, respectivamente em subdivisões com 10 camundongos cada.

A azitromicina (Zytromax - comprimido com 500mg; Laboratórios Pfizer Ltda, Avenida Tancredo de Almeida Neves 1111, Guarulhos, SP, Brasil; lote número 818 $64038-E)$ foi sempre ministrada durante 28 dias, por meio de sonda esofágica, diluída em água, a partir do dia em que infectamos os camundongos.

Como controle examinamos, a cada quatro dias, sangue obtido da cauda, após coloração pelo método

1. Laboratório de Parasitologia do Instituto de Medicina Tropical de São Paulo, SP, Brasil.

Endereço para correspondência: Prof. Vicente Amato Neto. Av. Dr. Enéas de Carvalho Aguiar 500, 05403-000 São Paulo, SP, Brasil.

Fax: $5511852-3622$.

e-mail: amatonet@usp.br

Recebido para publicação em 29/6/2000 
de Giemsa. Também observamos diariamente os animais, determinamos a mortalidade e efetuamos a análise histopatológica do fígado de sobreviventes, em preparações coradas por hematoxilina-eosina.
A escolha das doses foi feita, por analogia, com pesquisa experimental concernente à infecção pelo Toxoplasma gondi ${ }^{3}$. A antibioticoterapia foi interrompida no vigésimo-oitavo dia, diante dos resultados constados.

\section{RESULTADOS}

Parasitemia: Grupos I e III - presente a partir do sétimo dia após a inoculação, indo de 1 a 30 parasitas por campo até atingir progressivamente a quantidade de 61 a 100; Grupos II e IV: sempre ausente.

Mortalidade: Grupo I - 100\%, iniciada no décimo-sexto dia após a inoculação e estando todos mortos no vigésimo-quarto; Grupo III $100 \%$, iniciada no décimo-quarto dia após a inoculação e estando todos mortos no vigésimosegundo; Grupos II e IV - sobrevivência total.

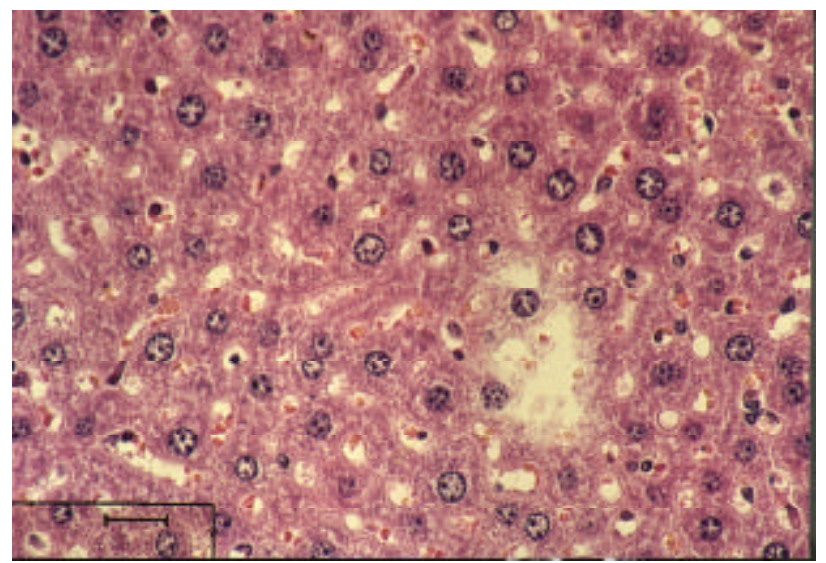

Figura 1 - Exame histopatológico de fígado (Grupo II, camundongos infectados e tratados $-100 \mathrm{mg} / \mathrm{kg}$ ): arranjo trabecular preservado, hepatócitos íntegros e ausência de pigmentação malárica (hematoxilina-eosina; 400X).
Análise histopatológica (fígado; hematoxilinaeosina; 400X): Grupoll - arranjo trabecular preservado, hepatócitos íntegros e ausência de pigmentação malárica (Figura 1); Grupo III - arranjo trabecular preservado, hepatócitos afilados com leves alterações degenerativas e intensa quantidade de pigmento fagocitado por células de Küpffer (Figura 2). A comparação fornece mais um concreto subsídio para analisar a ação terapêutica da azitromicina, pelo menos de acordo com a conduta empregada no Grupo II.

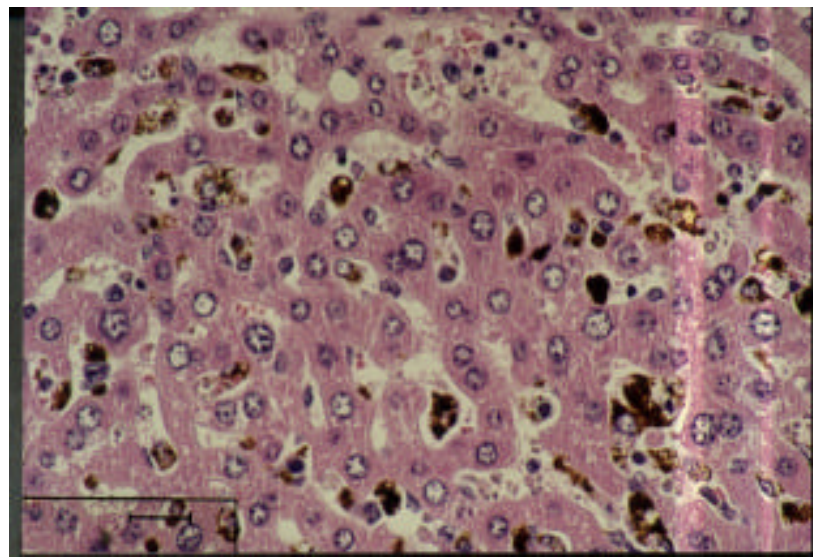

Figura 2 - Exame histopatológico de fígado (G3; camundongos infectados e não tratados): arranjo trabecular preservado, hepatócitos afiliados com leves alterações degenerativas e intensa quantidade de pigmento malárico fagocitado por células de Küpffer (hematoxilina-eosina; 400X).

\section{DISCUSSÃO}

A azitromicina agiu de maneira eficiente no sentido de debelar a infecção, quando usada a dose maior, conforme mostram todos os parâmetros escolhidos para averiguar a capacidade antiparasitária do antibiótico.

A presente constatação abre perspectiva para novas especulações, no sentido de estabelecer a posição da azitromicina na terapêutica da malária. Assim, propõese: iniciar o emprego em fases diversas da infecção experimental; usar doses variadas e durante períodos diversos; incluir outros tipos de plasmódios e de animais nas pesquisas; tentar desvendar o mecanismo de ação. $\mathrm{Na}$ dependência dos resultados obtidos poderão ser cabíveis ensaios terapêuticos em doentes, portadores de enfermidade para as quais há prescrição, atualmente, de múltiplos tratamentos, de acordo com diversificadas circunstâncias ${ }^{5}$.

Contudo, a propriedade antimalárica da azitromicina ficou demonstrada e, mesmo enquanto são aguardados esclarecimentos suplementares, no âmbito médicoassistencial determinados acontecimentos poderão receber adequada explicação caso tenha havido administração desse antibiótico empírica ou aleatoriamente, como ainda para coibir enfermidade associada à malária.

\section{REFERÊNCIAS BIBLIOGRÁFICAS}

1. Braz LMA, Pietro AOD, Amato Neto V, França FOS. Avaliação da eficácia da azitromicina e da pirimetamina, usadas isolada ou associadamente, no tratamento da infecção experimental de camundongos pelo Toxoplasma gondii. Revista da Sociedade Brasileira de Medicina Tropical 32: 401-403, 1999.
2. Derouin F, Chastang C. Activity in vitro against Toxoplasma gondii of azithromycin and clarothromycin alone and with pyrimethamine. Journal of Antimicrobial Chemotherapy 25: 708-711, 1990. 
3. Dumas JL, Chang R, Mermillod B, Piguet PF, Comte R, Pechere JC. Evaluation of the efficacy of prolonged administration of azithromycin in a murine model of chronic toxoplasmosis. Journal of Antimicrobial Chemotherapy 34: 111-118, 1994.

4. Kuschner RA, Heppner DG, Andersen SL, Wellde BT, Hall T, Schneider I, Ballow WR, Foulds G, Sadoff JC, Schuster B, Taylor
DN. Azithromycin prophylaxis against a chloroquine - resistant strain of Plasmodium falciparum. The Lancet 343: 1396-1397, 1994.

5. Prata A. A eficácia das atuais medidas de controle da malária: drogas antimaláricas. Revista da Sociedade Brasileira de Medicina Tropical 25 (supl II): 37-40, 1992. 